American Journal of Agricultural and Biological Sciences 4 (1): 49-62, 2009

ISSN 1557-4989

(C) 2009 Science Publications

\title{
Toward Clean Green Sustainable Development to Prevent the First Food World War, Changing Authoritative-Public Extension to Literalized-Partnership Extension System
}

\author{
Iraj Malakmohammadi \\ Institute for Social Science Studies, University Putra Malaysia 43400, \\ Serdang, Selangor, Malaysia
}

\begin{abstract}
Problem statement: The main purpose in this study is to provide a more rational platform in extension modeling to respond to the very recent world-wide warnings calling up for global revision of the present extension practices to put the appropriate science and technology to application to securing Clean-Green Sustainable Development (CGSD). Approach: To achieve this purpose, extension education was reconsidered through a new view lens of community empowerment. Results: The basic concern though, is based on CSD, self-sufficiency, food security and safety and entrepreneurship development in the agricultural sector and affiliated sub sectors. Fostering the development of catalytic leaders, researchers and educators who approach issues and challenges in research, education and extension from multiple perspectives and seeking to construct an integrated knowledge base upon which the practice of teaching, learning and human development is based are two other major concerns in this paper. Conclusion: Investigating factors that contribute to, anticipating rather than mitigating integrative extension education engineering, human potentials, human capital development, qualitative as well as, quantitative Clean Development Functional Literacy (CDFL) and evolution in science-push community-poll, techno-science extension practices are covered in this paper through an analytical qualitative research method.
\end{abstract}

Key words: Literalized extension, public extension, sustainable development, food world war

\section{INTRODUCTION}

All of us in the world are seeking life satisfaction one way or another, all along the life time. The level of our appreciation of our lives depends on the level of acknowledging satisfying responses from managing our knowledge to administer our life right towards fulfilling our expectations. Substantially, in terms of intellectual investment in the life cycle i.e., rational expectations and accurate knowledge management must be right to have the everlasting right appreciations. There are many policies, strategies and procedures to achieve high life satisfaction. Technology is not the main problem anymore considering the advancing research enterprises, tools and techniques. Certainly, lack of demand-led, partnership and efficient research and appropriate way of helping clientele to get the right image form the exposed research findings is our major problematic issue in development process. Accordingly, development has not that much to do with the research in general today, but definitely has lots of things to do with providing and introducing an efficient extension system in particular. Human development is a literacy- driven phenomenon, trickled down in to the community in a great part, if not all, as the result of literal liberalization and democratization. That is, a participatory-partnership, compatible extension system compacted with globalization, internationalization, regionalization, marketization, demand-driven, privatization, specialization and the like.

It should be contemplated that extension is not the magic stick to bring about the whole change in to the world of agriculture overnight, especially whilst public extension, unfortunately, suffering from majority of incompetent change agents with almost no knowledge and education in extension sciences. Certainly, we are facing big challenges dealing with extension inefficiency in different parts of the world today, tracing back to the absence of appropriate and, above all, responsive to the global warnings extension system.

Although the impact of extension on economic growth is out of question everywhere in the world, the bottom line of extension paradigm which is human capital development through agricultural literacy is major concern in extension paradigm, the unique extension stature that lamentably has not ever been

Corresponding Author: Iraj Malakmohammdi, Institute For Social Science Studies IPSAS, University Putra Malaysia UPM, 43400, Serdang, Selangor, Malaysia 
fully understood and accomplished, due to the encounter of numerous constraints and contradictories in blocking the road for extension to achieve its goals. As stated by Tripathi ${ }^{[1]}$, one of the possible reasons for this may be that the development models conceptualized and tested in industrial and academic institutions of western world were available for a well structured industrial sector, compared to primary sector, i.e. Agriculture. Adaptive changes are likely to happen continuously, even in the most advanced extension systems in fast developing countries. This is the very basic reason for states often to revising and readjusting their extension system. Investigating the extension and agricultural development literature during over four decades (1965-2008), reveals many studies, reports, guidelines and reference manuals provided by different countries, organizations and international agencies recommending constitutional changes in extension system to strengthen this system to responding to the critical questions in extension role in sustainable agricultural development, agricultural economic development, rural community development and human resources and/or human capital development is. Interestingly, economy, even in imperialist countries, is not the main concern in majority of the cases as much as human capital development. One potential example can be traced in the report made by Fulton et $a 1^{[2]}$, for the Rural Industries Research and Development Corporation (RIRDC) in Australia by a group of researchers in 2003 aiming to enhance human capital and facilitate innovation in rural industries and communities in Australia. Likewise, the $27^{\text {th }}$ FAO regional conference for Asia and Pacific ${ }^{[3]}$ already brought up to 30 notions in terms of the context of agricultural extension service system in Asia and Pacific among them precautions of having 4.2 billion population representing $50 \%$ of the world's total population by 2030 and requirement for human resource development through extension. Qamar ${ }^{[4]}$ reveals that the time is indeed ripe for policy-makers in developing countries to challenge and revisit the discipline of extension within a global context, so as to let the extension function be performed with excellence in line with the global challenges to their economies and especially to their agriculture sector. Cosmetic changes to the existing national extension systems will be of little benefit, as will be the repeated training of staff in stereotyped agricultural subjects. Modernization and reform of national agricultural extension systems as a major undertaking requiring careful analysis of the situation, comprehension of national policy on rural and agricultural development and food security, the leadership's vision of development for the country over the next 20 years or so.
Accordingly, it can be concluded so far that extension needs continuous and responsive changes to fulfill the expectations of present and future generations rather than the individuals or present community Per se.

To success this paradigm and pursue its purpose, extension education was reconsidered in this article as the main engine for agricultural functional literacy promotion or human capital development in agricultural sector [to change Human Resources (HR) to Human Capitals (HC)], also to mobilizing people with needed (felt/ unfelt) knowledge and technology through their partnership.

Agricultural extension is no longer just about to improving yields and producing food. Given the fact that, large number of subsistence farmers have to break out of poverty, this poverty is not just financial poverty but no question it is the absolute consequence or effect of other kinds of poverties as, information poverty, skill and competency poverty and cultural poverty in the first place.

Changing extension vision, mission, goals and objectives from exclusively materialistic to rationally realistic vista can secure a dynamic sustainable agricultural development to its practitioners through which they limpidly can realize that now, farming is far more beyond subsistence, i.e., it is not the way of living any more, rather it is a sustain way to making the life better, by providing better health, wealth and welfare for the whole community.

Extension apprehension should change from an exclusively imposed mitigate -materialistic ideology, to a codified incrementally domesticated, democratic, scientific, cause-effect and human empowerment, realistic ideology, alleged to resolving the crucial endangers and serious challenges ahead of the present and consequently prosperous generations, in terms of Global and Subsequent Anthropogenic Warnings as follows.

However, extension is not only about to bring change in unfavorable present situation to stakeholders, but also to preventing problem creation for the sake of the prosperous generation as well. This is the duality of extension duty. That is, to empower partners to find, solve and implement solutions to the present problems, from one hand i.e., diagnostic and remedial role for which extension needs to date furbishing or updating approach and to foreseeing the emerging developmental problems by enhancing functional literacy and predictability among the partners, from the other hand, i.e., prophylaxis role for which extension needs future furbishing or over dating outlook. 


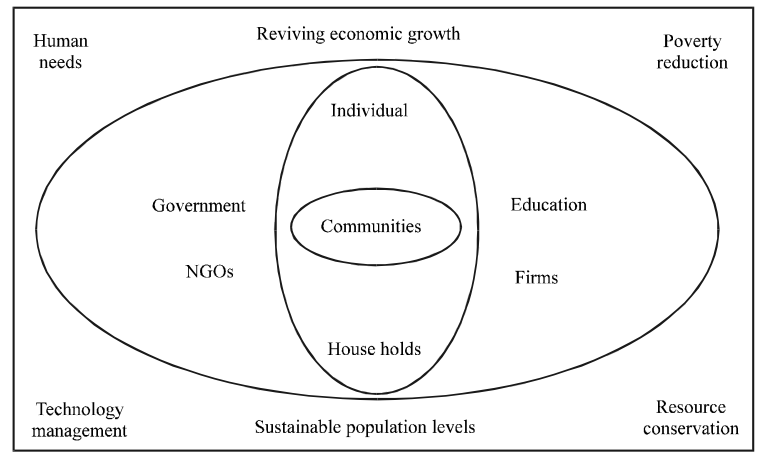

Fig. 1: Dimensions of sustainable development ${ }^{[27]}$

Global warnings: Followings are some fundamental global warnings to us in brief to consider in reengineering extension education to creating intuitiverewarding change environment for extension partners.

- Rapid population growth in a way that at the day of writing this page $(04 / 04 / 08)$ the world population was $6,659,111,122$ which will exceed $7,600,486,063$ including 3,819,803,284 male and $3,780,682,779$ female by 2020 which means 941374941 more than what we already have ${ }^{[5]}$

- Global warming due to the emission of Green House Gasses (GHG), i.e., $\mathrm{CO}^{2}, \mathrm{CH}^{4}, \mathrm{~N}_{2} \mathrm{O}$, HFCs, PFCs and $\mathrm{SF}_{6}{ }^{[6]}$

- Present agricultural community is getting quite aged and gradually retiring

- Some active farmers who cannot afford farming or do not receive from agricultural job as much as they expect a alienate belongings and leave the agricultural community

- Reciprocality of vulnerability to natural disaster, poverty and food insecurity ${ }^{[7]}$

- Climate change poses a serious challenge to social and economical development. Developing countries are more vulnerable because their economic are basically more dependent on climatesensitive natural resources and because they are less able to cope with the impact of climate change ${ }^{[8]}$

- Young generation even in agricultural community is not willing that much to day to get involved in agricultural job, because of the possibility of easier and more earnings from other sectors

- Harvests have been seriously disrupted by freak weather, including prolonged droughts in Australia and southern Africa, floods in West Africa and this past winter's deep frost in China and recordbreaking warmth in northern Europe due to the climate change
- Many natural resources are divesting (soil, water and minerals)

- Many consumers are buying ever-greater quantities of food

- Those that didn't have enough cash to buy what they needed before now have enough to buy a lot more

- For most people, food prices are rising faster than earnings ${ }^{[9]}$

- Many producers have already stopped even growing their own food

- Global stockpiles of some basics have dwindled to their lowest point in decades

- The spike in oil prices has pushed up fertilizer prices as mentioned by the head of the International Monetoring Fund (IMF) on Sunday, 13 of April, 2008, warning governments about rising inflation that could have terrible consequences if it continues and urged them to take immediate action ${ }^{[10]}$

- The shift to biofuels production has diverted lands out of the food chain ${ }^{[11]}$

- Biotechnology [and nonotechnology as well] is impacting the structure of agribusiness with the integration of genetics, seed production and agricultural chemicals. The convergence of biotechnology with other innovations such as ICT, satellites and Global Positioning Software (GPS) has altered the farming and marketing system ${ }^{[12]}$.

All of these can push the whole world toward an inevitable Food World War in the few years to come, if the recent crisis remains unsolved. Then the biggest warning and the greatest anthropogenic disaster will happen.

Subsequence anthropogenic warnings: Followings are few of many subsequences of unresolved or inextricable global warnings including decreasing number of producers and increasing the number of consumers and subsequently, unbalancing the food economy to the favour of speculators.

- Cost of trucking food from farms to local markets and shipping it abroad is much higher dealing with high price of oil

- The push to produce biofuels as an alternative to hydrocarbons has increased

- Smiths ${ }^{[11]}$, reffered to Beddington as he said: by 2030, rising world populations would require a $50 \%$ increase in food production, Professor Beddington said. By 2080, food production must double 
- The rush to biofuels-allegedly environmentally friendly-meant increasing amounts of arable land were being given over to fuel rather than food

- Already biofuels have contributed to rapid rises in international wheat prices. Luring thousands of farmers away from growing crops for food by generous subsidies for ethanol

- The creeping fear that the world might actually run short of food has led speculators to pour billions into commodities, further accelerating price rises

- Agricultural waste is uprising since it has remained unmanaged

- The price of staple food (Wheat, rice, corn and...) has increased drastically

- Donations from international aid funds and organizations are lowering every day

- Hunger and malnutrition are rising faster and subsequently threatening the world's health and stability

- Not only since Asopa and Beye ${ }^{[13]}$ stated in 1997 but, much further beyond and much further after that, Research problems being investigated are generally not in accordance with the priority needs of agricultural producers and knowledge generated at research stations has not been effectively transferred to producers

Consequences: Half the planet depends on rice but stocks are at their lowest since the mid-1970s when Bangladesh suffered a terrible famine. Rice production will fall this year below the global consumption level of 430 million tones ${ }^{[11]}$.

Rice a staple for billions of Asians has soared to its highest price in 20 years, while supplies are at their lowest level since the early 1980s, according to the U.S. Department of Agriculture. Meanwhile, the global supply of wheat is lower than it's been in about 50 years just five weeks' worth of world consumption is on hand, according to the U.N. Food and Agricultural Organization.

Walt ${ }^{[14]}$ stated that for the world's poorest people, the price spikes are disastrous. AID officials say that millions who previously eked out enough to feed their families can no longer afford the food in their local stores and are seeking help from relief organizations. $\mathrm{He}$ also alleged from Sheeran, executive director of the U.N.'s World Food Program when she said: we are seeing a new face of hunger and "People who were not in the urgent category are now moving into that category.

A cruel reality is taking shape in millions of desperately poor households. For a family of five living on just US\$1 per person per day, a doubling of food prices effectively cuts $\$ 1.50$ out of their $\$ 5$ daily budget. That leaves the family no choice but to consume less food and lower the quality of their diet. As nutrition deteriorates and access to services such as health care and education diminishes, the family's prospects for overcoming hunger and poverty become more remote than ever ${ }^{[12]}$.

Hundreds of thousands of people will be starving..., leading to disruption of the economic environment. Development gains made in the past five or 10 years could be totally destroyed, the issue goes beyond humanitarian concerns ${ }^{[10]}$.

According to IFPRI calculations, a moratorium on biofuel production in developed countries through 2008 would ease corn prices by $20 \%$ and wheat prices by $10 \%{ }^{[15]}$.

Voters in many countries, blame their governments in harsh situations, as of 2008, in part because they could no longer afford staple foods. People want a person who can fix this problem.

Solutions: To painless people who have never experienced difficulties in running their life, the only silly alternative to their breakfast bread problem can be prescribed as: Let Them Eat Cake? To resolving the serious community hunger problem when they hear that people are facing serious feeding crisis but, Who Can Afford Cake?

A contemplative solution: In case of extension, this is the time for us to listen to the voiceless deprived rural farmers and technology-imposed extension stakeholders when they say: no more technology transfer please. Just let us in the process of generating the technology we need and creating the better life we deserve.

To overcoming the growing problems and obstacles along the sustainability development, calls up attentions to creating a favorable intellectual conservation atmosphere and change-encouraging environment to empower extension partners to leading themselves to: managing their knowledge and expertise, recognizing and resolving problems, implying well adapted and monitored solutions and invest their valuable tacit knowledge to sustainable human development as creative partners of zero-emission, sustainable clean agricultural development(ZESCAD).

This is the most concerned issue that has called and is continuously demanding extension to change, with different recitations of course, as was found, for instance in ${ }^{[1-3,16-25]}$.

What is called up worldwide so far to change, cannot ever resist to change and has to admit the change anyway however, the sooner the better. In order for extension to be successful in creating a desired change 
environment, it has to adjust not only with past on and on-going change flew of development to be updated, but to be prosperously upgraded ahead of the current development trends to prevent evitable problems to generate in the future.

Extension fix will take time because of the complexity of the issues and the number of parties involved. We need to empower our farmers so that they can be active partners in the whole process of development. Otherwise they will continue to be passive. Presumably, time for extension is clicking much faster than it does for the others, because of extension flagmanship the whole agricultural adjustment to the desired and expected changes to sustaining a better future, not exclusively for the agricultural community per se, but for the whole world. This is what has made the extension a unique boundaryless and limitless human enrichment phenomenon to secure clean development. i.e., Clean Development Extension Education (CDEE). Contributing to the development of such a compatible system with regard to the extension goals and global priorities, will be one of the most important tasks of agricultural extension specialists from now on.

The primary vision of agricultural extension is gain, adapt and disseminate a combination of appropriate life and professional technologies to assist farming community and consumers who are dealing with agriculture, natural resources and environmental issues to re-branding, re-fashioning and refreshing their life, adapting their production and marketing strategies to rapidly changing social, political and economic conditions so that they can, in the long term, shape their lives better according to their personal preferences and those of the community toward more job and life satisfaction and appreciation. This is why Texas Cooperative Extension, that have served Texans for a combined 224 years, began 2008 with new names of AgriLife Extension and renewed missions, after two years of study and planning. The purpose for this meaningful change was described by Hussey ${ }^{[26]}$ as, We are making these changes to better communicate the life-sustaining and life-changing impacts that both AgriLife Research and AgriLife Extension deliver to the people of Texas and beyond.

Extension's Global Priorities to maintain CGSD, i.e., solving present problems and prevent prospectus obstacles to bother CGSD in the third millennium are:

- $\quad$ Fulfil functional literacy

- Job satisfaction, happiness and life appreciation

- Diminish human erosion

- Develop human resource capital
- Building Institutional capacity

- Secure ecological sustainability

- Develop productive resources

- Resource conservation

- Food safety and security

\section{MATERIAL AND METHODS}

This is a qualitative theoretical and practice-based research, conducted through literature review coupled with four decades of field and professional experiences, to build up a new look to strengthening extension, through designing models to explain the essence and nature of extension work along with compatibility of extension and knowledge management, to preventing the greatest imminent anthropogenic disaster i.e., Food World War.

\section{RESULTS AND DISCUSSION}

As mentioned earlier, population is continuously increasing is the world basically, in developing countries. Therefore, increase in food demands, as well as the other nature based products, puts increasing pressure on most of the natural resources, if not all and consequences land degradation, land fragmentation, lower productivity, deforestation, shortage of water and other scarce resources. Moreover, while these natural and/or man-made disasters are occurring, a multi facet human erosion phenomena, along with it's devastative consequences such as, unemployment, economic inflation, lack of livelihood, intellectual poverty (agricultural literacy, knowledge management, information technology, development communication) is elevating rapidly.

The solution to the turmoil in the human and natural resources is the means and tools for cultural, social and economic advancements, especially in rural areas in developing countries. This situation addresses to a contemplative solution to infrastructure human capitals and devastating natural resources management, i.e., sustainable development as the wisest way of enhancing multi-dimensional development.

In simple terms, Sustainable development refers to maintaining development over time but, so far, there are well over four hundred definitions of SD currently available in the literature. The most frequently quoted definition is from the report Our Common Future (also known as Bruntland Report) that defines SD as development that meets the needs of present without comprising the ability of future generation to meet their own needs ${ }^{[27]}$, as illustrated in Fig. 1. 
However from the above illustration, education is considered to be the key issue in achieving SD and therefore, there is an urgent need for strong commitment to education and training in all countries.

We may be able to use the Earth Trends statistics in terms of agricultural indices ${ }^{[28]}$, as one of the major criteria to assess the efficiency of agricultural knowledge management system to competing one another in wiser usage of the limited resources in producing more agricultural products with less harmful consequences or side effects, which is clean green sustainable development.

Contemporary questions: Given the tragic consequences of human and natural resources erosion and more importantly food price crisis, most developing countries in realizing the endanger and serious global warnings in the near future, are asking the following questions in revising and re-infrastructure their agricultural extension system.

- What have we done in the past?

- What have we paid for doing things wrong?

- What have we got to doing things right?

- What should we do for the better future of our human resource capital?

- What are the bests and doing the best things best nationally and internationally?

- What are the implications of the experiences for the more efficient and suitable Extension Service in the country?

Following actions need to be taken seriously to responding to these questions.

Bringing agriculture back on the agenda to sustain food safety, security and sufficiency and that within agriculture, revitalize and insure agricultural community against natural and manmade disasters to achieve socio-economic balance.

Implementing UNFCCC Artivle.6 (Education, Training and Public Awareness) as in case of Turkey ${ }^{[29]}$ along with safegarding agricultural practiciers against global warnings.

Enriching client-driven partnership extension approaches (CDPE).

Extension maturation and modernization: The emphasis in agricultural extension must be in the integrated approach in which all aspects of development are taken into account and embodied in a balanced program. Integrated extension education calls for comprehensive partnership improvement aspects of rural life and transformation of rural attitude from farming as the way of living to a sustain way of making the life better, through providing better health, wealth and welfare for the whole agricultural community, as stated before. It would not be that easy definitely, to change the client's attitudes and life style simultaneously, especially when extension substantially is dealing with its weaknesses (internal constraints) and plagued in with its opponents, those who are namely positivists. This has been and will be the biggest challenge for extension indeed to qualitatively sympathize quantitative mind sets and believes of even highly educated opponents. Moreover ${ }^{[23,30-32]}$ also believe that extension is often undervalued by organizations that do not understand the value of sound extension processes and how they can speed up the rate of adoption through creating the right environment for adoption and change. Extension in agriculture is about facilitating or creating the right environment for change to be adopted using new technology, innovations, methods or systems that benefits industry as well as the end user-the farmer. While it is one thing to use extension techniques to increase awareness and transfer information, it is considerably more complex to create an environment that leads to adoption and change at the ground level.

Solaiman $^{[21]}$, as well as many other extension specialits, has recognized well that extension is clearly facing challenging times in Asia. Instead of prescribing reforms, the policy process should ideally facilitate continuous incremental change through experimentation, reflection and learning. These new challenges mean that extension and extension policy need to tackle a diversity of objectives that include but go beyond transferring new technology.

The challenge arises from the notion of availability and commonality of extension in contrast with the notions of excludability (if individuals don't pay, they don't receive, i.e., user-pay in extension literature) and subtractability (one person's consumption excludes others from receiving it, i.e., privatization in extension literature) that come from Carney's economic classification of goods and services ${ }^{[24]}$, although, according to this classification, extension can be considered as a public good. Besides this, Fig. 2 comprises worldwide challenges to extension and development schemes confronting extension respectively.

Besides, going over the history and reviewing extension revolution movement reviles many internal constrains bothering extension to manipulate required change. Some common major internal constraints are: low level of extension expertise, lack of technological 


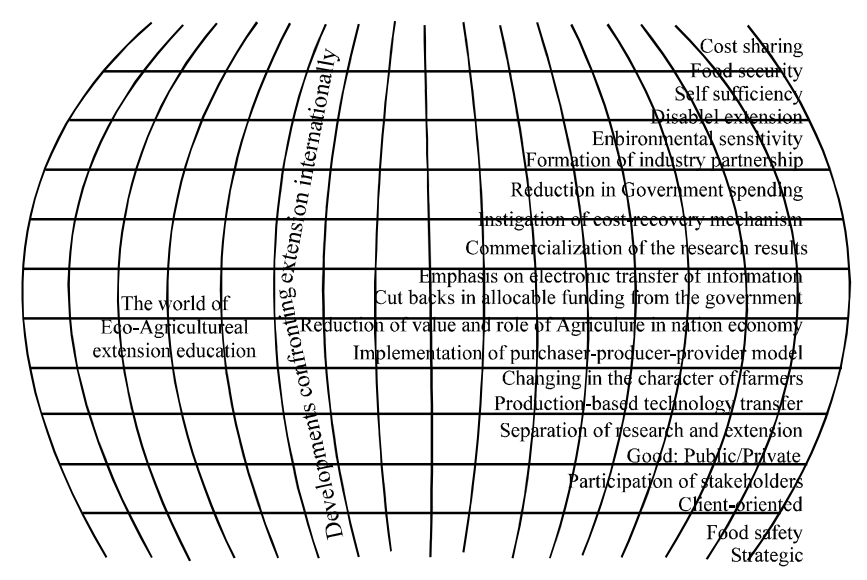

Fig. 2: Extension international maturation and domestic modernization ${ }^{[22]}$

specialty and behavioral management proficiency, weak linkage to research institutions and almost no linkage to other institutions especially academic institutions, high level of bureaucracy and low level of autonomy among the extension personnel, low level of job prestige, fulfillment and promotion, parallel, multidisciplinary and lose (disconnected) extension offices, low level of NGOs involvement, lack of appropriate extension legislation, lack of knowledge about future roles and responsibilities of extension and extension internationalization, high discrepancy in extension ideology and methodology, vagueness in extension policy, strategy and practice towards present and prosperous internal and international expectation, low or even zero level of intrapreneurship development and lack of interest in overcoming barriers of farmers participation, lack of potential innovative approach to the professional development of extension personnel, lack of research and practices on facilitating end enhancing on farm learning process, unplanned institutional change and organizational restructure in Low interest on updating and upgrading extension management, low or zero emission partnership in extension projects, inappropriate and old or no model for extension and extension evaluation to operate better. Extension challenges also can be classified into the three categories up to now as: policy challenges including: food security, food quality and related issues, clean environment, social equity, sustainable agriculture, contribution of private sector, national strategy and reform process, new and emerging challenges including: new extension clients, urban agriculture, global market and diversification (high value crops, lucrative market, high tech-agriculture, bio-diversity, globalization, marketization, system management and leadership challenges including: national-driven, multi-sector, multi-disciplinary, multipurpose, multiple extension, decentralization, private service delivery, privatization, contracting, private market-based service, demand-driven (demand driven programs, participatory approach, producer organization), revitalization, leadership (Farmer-lead, farmer organization, client-driven), liberalization and finally globalization.

Those who are not that familiar with the nature and essence of extension do not fully realize that extension cannot accomplish the whole development, all in one night. To furbish the extension that people demand today and for the extension to flourish to properly respond to the new era expectation, extension is being recognized as the responsive to positive desirable changes in professional behavior and habits of its clients towards human capital development, considering both producers to produce more and better quality products and consumers to utilize products wiser and prevent waste. This needs a serious shift from pure positivistic Mode $_{1}$ (investigator-initiated and disciplinebased), to $\mathrm{Mode}_{2}$ research (problem-focused and interdisciplinary) at the first place ${ }^{[33]}$.

Drives towards extension reforms should not be utilized only to cutting back the public fund that already has generated attributive obstacle against the care and share extension constitution in empirical countries, as well as devastating consequences in some developing countries that unintentionally copied this strategy, but to abalienate extension to the capable and leading potential hands in partnership-demand-driven perspective. To initiate evolutionary changes in the changer (extension), extension has already accomplished many dynamic maturation stages, comprehensively according to the potential circumstances in its milieu. 


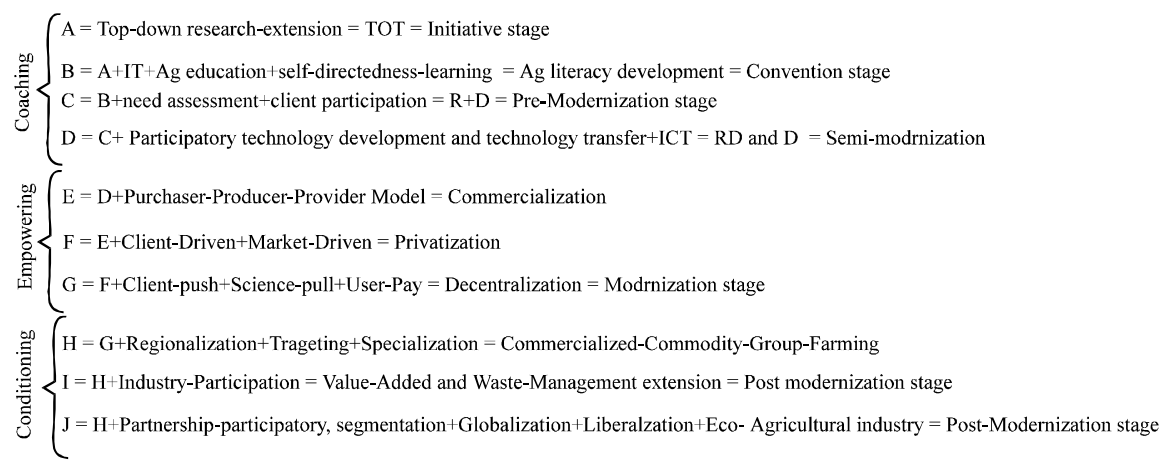

Fig. 3: Major sequential evolutionary stages and trends in extension maturation arena

Viability of extension reveals that each circumstances deserves a specific extension stage in maturation cycle and subsequently, each extension maturation stage just suits the deserved circumstances. Other than this, it would not work sufficiently, if not being corrupting. Certainly, in corrupting cases, this is primarily the extension specialists to be blamed for extension failures and its unfavorable consequences and no one else among the extension practitioners.

Many countries have changed their agricultural extension system within past three decades but what has been done two times in Australia in terms of creating expert study teams to investigate Australian, as well as other country's extension system is well appreciable. For instance, in an analytical study handled by Fulton $e t$ $a l .{ }^{[2]}$ to restructure the Australian agricultural extension system, they identified four key areas to creating demand for learning and change that can be followed by others who are after change in their extension system as follows:

- Institutional change and organizational structures supporting learning and change including extension policy, improve extension provisioning, examples of extension systems displaying positive characteristics

- Professional development of farm advisers including their structural arrangements and careers

- The facilitation of enhanced learning/change process on farm including focus on client needs, design effective learning programs, groups, new technology and publications and some other approaches

- Better understanding of the barriers to participation in learning opportunities
As is indicated in Fig. 3, there are 10 stratified evolutionary stages in the history of extension starting from top-down Transfer of Technology (TOT) as initiative stage and ending with ultra modernization stage. Development of the latest stage in the future as far as strategic extension campaign is concerned will be inevitable for the time being. No one should expect to get a higher stage without passing former required stages. Unfortunately, some developing countries just copy extension model from industrialized developed countries regardless of the prerequisites and consequently, claps along the way. As extension is the right thing for the right people at the right place and of course at the right time, therefore it doesn't look that wise just to copy extension models without being capable enough to implement it properly only to show that you are coping with the developed world.

Literalized-partnership-democratized extension approach: Six launching platforms for extension movement in relation to agricultural literacy or Human Resource Development (HRD) and agricultural illiteracy or Human Resource Erosion (HRE), are illustrated in Fig. 4. The higher the developmental step and partnership level, the higher the human resource develops and the lower the human resource erosion gets. In fact this developmental extension hierarchical model is directly impacted by agricultural literacy coupled with partnership, rather than just participation, in favor of human resource development and against human resource erosion. Other words, the more mature the extension gets, the more efficient it will be in its maturation and modernization cycle and therefore, the stronger it gets to luring development obstacles away from the partners, through agricultural literacy enhancement. 


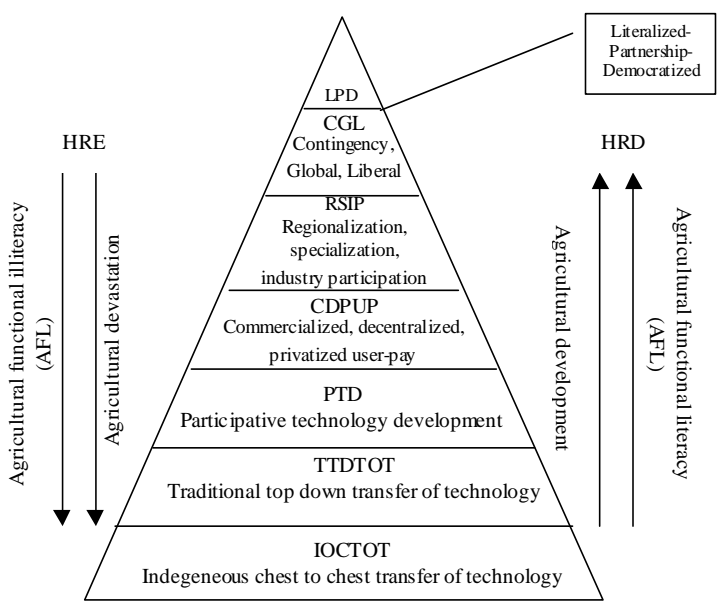

Fig. 4: Hierarchy of extension modernization to HRD elevation and HRE abolition ${ }^{[22]}$

As to date, diversity of extension challenges is crippling traditional, conventional, pluralistic public extension approach as shown in Fig. 5. Although,

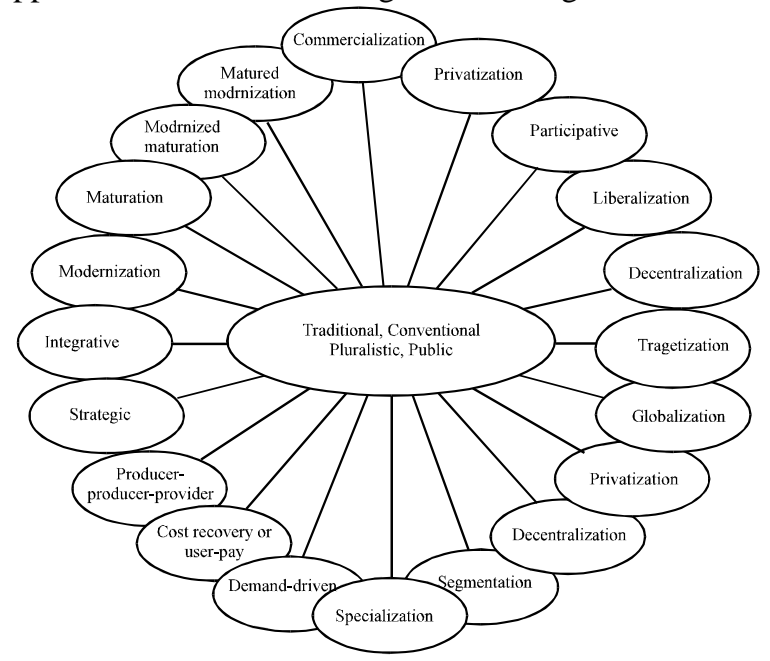

Fig. 5: Diversity of extension challenges are crippling traditional, conventional, pluralistic public extension approach

extension policy makers and administrators cannot and should not globalize their extension system in a way to embrace all the challenges, but they are encouraged to reengineer the system by applying the most appropriate incremental approach to be able to respond to these present and emerging challenges properly To achieve and implement appropriate approach, extension needs much more than just furbishing, re-fashioning or re- branding, i.e., extension needs the best ingredient of maturation and modernization to cope.

To achieve and implement appropriate approach, extension needs much more than just furbishing, refashioning or re-branding, i.e., extension needs the best ingredient of maturation and modernization to cope Advanced approaches. Figure 6, reveals four possible positions to be taken by extension as the result of this amalgamation depending on the circumstances of the extension system. Each one demands its own requirements. That is, no extension system will be able to work, if it is misplaced in maturation/modernization matrix. This is why imitating advanced extension model with no scientific and technical logic or just refashioning or re-branding the existing extension mode in developing countries will not make the benefit to the end-users.

\begin{tabular}{|c|l|l|}
\hline Motorization & \multicolumn{1}{|c|}{+} & \\
\hline+ & $\begin{array}{l}\text { Immat ure/Indi- } \\
\text { geneous: } \\
\text { Subsistence, trial\& } \\
\text { Error }\end{array}$ & $\begin{array}{l}\text { Immat ure/ Modernized: } \\
\text { Imposition, imit ative }\end{array}$ \\
\hline- & Mature/T raditional & $\begin{array}{l}\text { Mature/ Modernized: } \\
\text { PTD, HRD, HRCD, } \\
\text { PLO, SDL, LPD }\end{array}$ \\
\hline
\end{tabular}

Fig. 6: Extension maturation/modernization phases

Generative extension: To be generative, extension should contemplate the system reengineering by applying suitable ingredient of its mix as shown in Fig. 7.

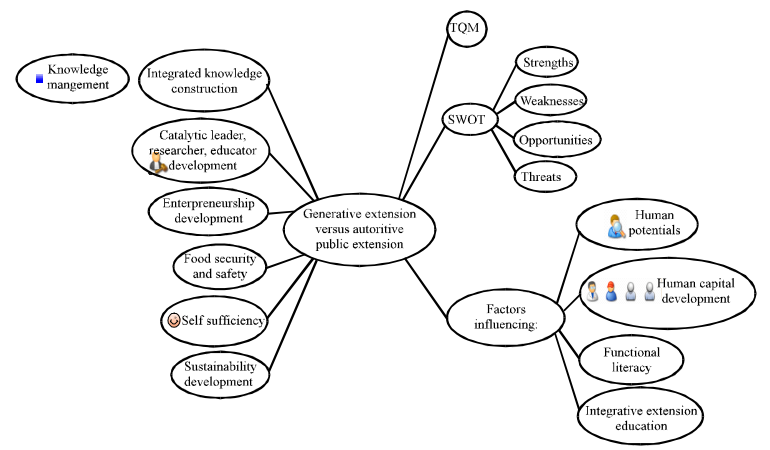

Fig. 7: Rationalizing extension mix from authoritydriven to generative approach 
Figure 8, in turn, illustrates the systematic arrangements of increasing and decreasing forces pertaining extension cross section of rationalization.

Extension is, thus, to improve interactions among actors within AIKS so that farmers have optimum access to any information that could help them enhance

Extension $=\mathrm{HRD}$ processor, mindware and behavior rationalizer

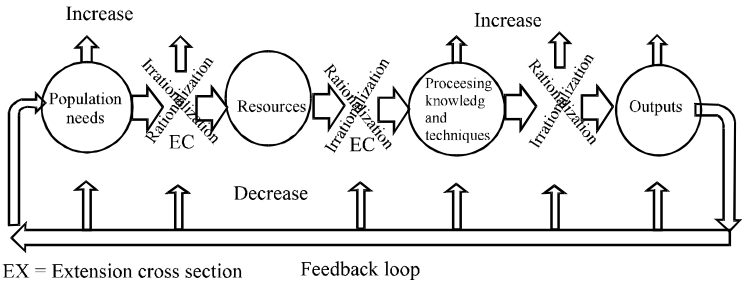

Fig. 8: Systematic arrangements of increasing and decreasing forces pertaining extension cross section of rationalization

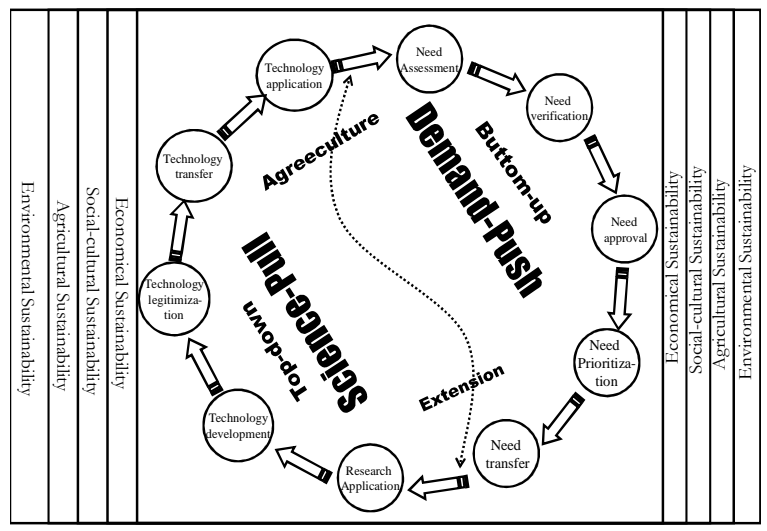

Fig. 9: Two axis partnership AKMS model

their economic and social life situation. Agricultural extension, in its prime stature, is then the agreecultural development between actors within AIKS. This mediating function focuses on improving those relationships that promise to be most beneficial to farmers. Figure 9, shows the interaction of AKIS partners based on two axis to achieve agreecultural development.

This model cannot be applied in community empowerment unless the systems in charge, Immerse, enliven, intermingle, incline research, education and extension system to unleashing human potentials, activate human dynamics to enhance sustainable democratic human development enterprise:
- Assess needs

- Develop science and technology

- Train applicants to apply science

- Apply science and technology on the field

- Encourage participation

- Unleash human potentials

- Activate integrated intuitive-rewarding education

- Activate human dynamics

- Enhance sustainable democratic human development enterprise

Knowledge management application in extension: Knowledge management is the process of transforming information and intellectual assets into enduring value. It connects people with the knowledge that they need to take action, when they need it $^{[34]}$.

Complementing what Bellinger ${ }^{[35]}$ stated, based on Fleming's as a basis for thought, with philosophy of extension, generates a more complex diagram (Fig. 10), to emphasize the position of knowledge management as the basic sub-mix to extension, revealing that extension is maturation in knowledge management in deed.

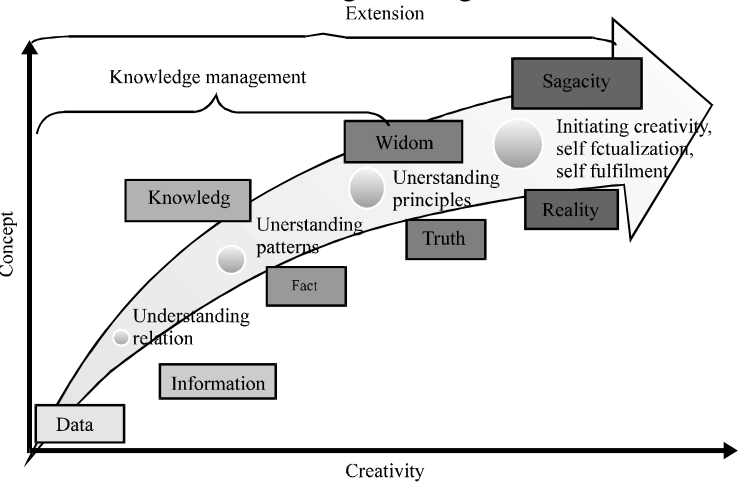

Fig. 10: Position of extension comparing to knowledge management, adapted from Bellinger ${ }^{[35]}$

Given that knowledge management to be the basic submix to extension, many commonalities could be found in their vision, mission, objectives, goals and methodologies. Although, extension is the complementary phase of knowledge management in investigating and achieving the reality but, knowledge management is performing as the launching platform for extension accomplishments.

Therefore, in this sense, extension starts with knowledge management and ends up with human enrichment. As indicated in this figure, though, the bottom line of knowledge management is wisdom, whilst, the bottom line of extension mix is human fulfillment self actualization and life appreciation Fig. 11 maps the road for voluntary change within the 
amalgamation of basic agricultural development mix and knowledge management mix.

This model creates a virtuous loop between researchers and technology appliers from the very beginning of the process, the end users of research findings are engaged right from the beginning.

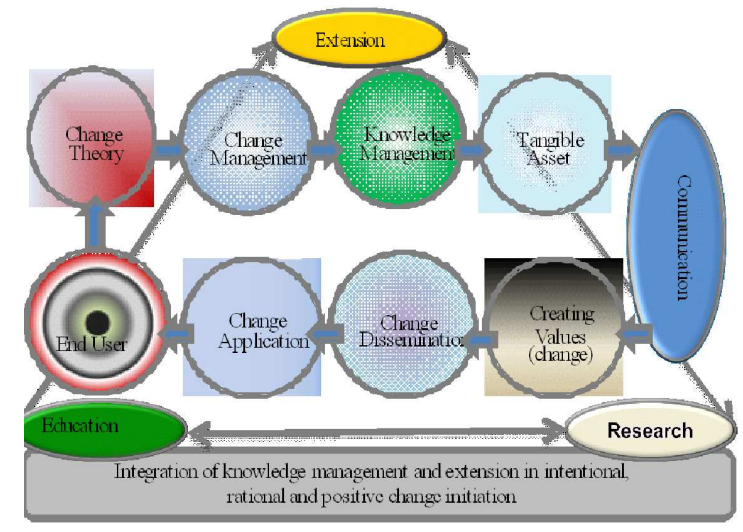

Fig. 11: Agricultural extension and knowledge management MIX

While in a traditional approach to research, the researcher designs and carries out the research project in isolation with very little input from farmers themselves, the knowledge sharing approach which engages researchers and users allows for local innovations and conditions to be accounted for and hence has more chance of success. Some other basic expected benefits from this model to extension partners especially to the end appliers are:

- Support and enable agricultural innovations systems

- Local farmers and researchers work together in both discovering and developing local innovations

- Interaction between different actors to generate knowledge

- Smallholders do not innovation alone, they are embedded in networks

- While networks are important for innovation, there is a need for new actors and a greater diversification of roles and responsibilities as well as forward looking policies to promote the entry of private agents and diversification of public roles

- Little emphasis in knowledge management has been devoted to broader issues relating to the nonfarming sector

- More attention is being paid on knowledge sharing and generation between many types of stakeholders who rarely interacted in the past, emphasis is still
- More importantly, changing passive and incapable indigenous knowledge with active and productive modern knowledge

\section{CONCLUSION}

It can be concluded from what has been presented so far that:

- Several turning points in the history of extension encourage us to promote the change atmosphere to respond to new development policy and public demands

- Extension Systems must be flexible and change as world-wide warnings are being issued and therefore, policies, technologies and the needs of farmers change accordingly

- Extension is an incremental world-wide reflection to anthropogenic consequences of functional illiteracy

- As extension is a discursive catalytic movement vanguards sustainable development, it is important to know our own extension system's weaknesses, strengths, threats and opportunities to codify the new appropriate extension system

- Extension is Agree-culture in our Life and our commitment to live it right deals with the major movements of restructuring agricultural community. Therefore it can be renamed as agreelife-culture

- Research-Extension Linkage means: agree-cultural development in working with the partners and helping them to make the best decisions in realizing the right things and making commitments to doing the right things right

- Although there is no one best system/model suit to all circumstances, an analytical investigation on strengths and weaknesses of our own extension system along with learning from other extension systems and their strengths and weaknesses can bring us to a closer outlook in providing more internally and externally efficient extension system

- Agricultural Knowledge Management System and Research Extension Linkage along with on the ground experiences identify few basic benchmarks along with some common useful global principles applicable across nations as possible general framework for agricultural development

- Cosmetic changes to the existing national extension systems will be of little benefit, as will be the repeated training of staff in stereotyped

- Agricultural subjects. What remains is a normative framework for internationalizing and or regionalizing extension to bring different countries to global agreements and persuading them to care and share on CGSD 
- Domestication of global CGSD agreements based on the circumstances and conditions fosters Strategic Research/Extension Campaign (SREC) to strengthen research/extension linkage to bring countries under one umbrella

- Contributing to the development of such a compatible strategy must be one of the pivotal tasks of international agricultural agencies from one side and developing nations from the other

- We have to prepare and if there's a need which is indeed, to take action rather than just to talk idly.To be effective, extension organizations need revitalization, intraproneureship development and being prepared for the foreseeing new changes to come. At the same time, extension agents need knowledge, expertise and competency to create the right environment for desired changes to occur

- In doing so extension needs to change it's mind map so far, from, materialistic to realistic, participatory to partnership, authoritative to democratic, trickle-down to bottom-up, clientele to partner, public to strategic, bureaucratic to dynamic and passive to active

\section{RECOMMENDATIONS}

Given the fact that science and technology, in some cases somehow, are getting ahead of time to preventing deficiencies to happen, from one hand and difficulties in feeding the world properly are rapidly growing along with some major political, socio-economic, cultural issues and obstacles, then the era of updating (to date furbishing) that usually is being applied in normal circumstances through diagnostic remedial extension. This rings the bell for extension to be prepared for a new generation to deliver i.e, Future-Furbishing Extension Approach (FFEA) or prophylaxis extension, especially in the most vulnerable areas of the world such as Asia and Pacific Region that accounts for 57\% of the world's population (nearly 3.2 billion), about half of that population will be younger than 25 in 2010, more than $80 \%$ of the world's smallholder farmers and $73 \%$ of the total farming households live in, two-thirds of the world's hungry and poor are found here, 800 million people who are poor and 500 million of them who are malnourished.

There have been good trend along with the challenges: over a three-decade period, food production in the region more than doubled. But the demand for food and agricultural products is going to increase $60 \%$ in the next 30 years which is of major concern as the per hectare yield of cereals needs to increase by one tone. As well, production resources, such as land, water and biodiversity are shrinking and degrading. Total factor productivity growth has decelerated and yields of cereals are stagnating. And investment in agriculture is declining. The continuing high rate of illiteracy and the migration of rural women contribute, along with other significant factors, to the limited impact of the information revolution. In reaction to the fore afoot, there has been poor policy response formulation and implementation of regulatory measures and standards, including the codes of conductor for responsible fisheries, sustainable use of forestry resources, food safety and biosecurity ${ }^{[36]}$.

Due to the obsolete turmoil in agricultural extension system in the world especially in Asian countries, dealing with global alerts and threats to extension reform from one hand and vulnerability of agricultural industry to secure the demands of the internal and external commodities from the other, establishment of a nonprofit international catalyst organization (may be named Asian Catalyst Extension Organization ACEO) to furnish multilateral alliances among member countries to flourish their extension aspirations is inevitable. This organization will be rendering following services to country members:

- Creating Asian extension continental, regional and local constitution

- Conducting comparative analysis studies in Asian countries in extension and agricultural-life education status quo

- Establishing an Agri-Life Extension development fund to help poor in rural areas provide a better life

- Establishing Asian agricultural extension and education faculty, research institute and vocational education center

- Establishing an official newscast agency and press (scientific journal and magazine and newspaper...) to keep member countries informed and updated

- Creating a web site for extension enquiries and knowledge management

- Design the appropriate extension model based on the extension constitutions and demands from countries

- Offering seminars, workshops and meetings in hosting member countries

- Creating a platform to promote distinguished researchers, lecturers, extension specialists, extension agents, extension partners, farmers and... in terms of the Asian Extension Olympiad

- Rendering pilot project to explore participation motives and constraints

- Motivating intrapreneurship in extension organizations in country members, 
- Creating a body of extension dog-watch to certify country member extension system with and AEO (like ISO) certificate following specific standards

- Conducting annual extension conference in country members to promote extension research and disseminate research findings

- Establishing extension fair along with the annual conference

- Establishing a body of extension media production to produce and sell books, tools, Medias and techniques (softwares and hardwares)

- Establishing a country chapter in each country member

- Stressing extension modeling in each country following rules and regulations of the ACEO

\section{REFERENCES}

1. Tripathi, B.D. Agricultural extension personnel in new millennium- A perspective view. Manage cyberary, National Institute for Agricultural Extension Management. Ministry of Agriculture, India.

http://www.manage.gov.in/managelib/merr/index.h tm

2. Fulton, A. et al., 2003. Agricultural Extension learning and change. Rural Industries Research and Development Corporation (RIRDC). Canberra, Australia.

http://www.rirdc.gov.au/reports/HCC/03-032.pdf

3. Food and Agricultural Organization (FAO), 2004.

First report on the state of the world's animal genetic resources-progress report. http://www.fao.org/DOCREP/MEETING/007/J170 5e.HTM

4. Qamar, K., 2005. Modernizing national agricultural extension systems. A practical guide for policymakers of developing countries. http://www.fao.org/docrep/008/a0219e/a0219e00.htm

5. Census Bureau International Data Base (CBIDA). 2008. Population by age and sex. United States International Date base, Washington, USA.

6. Vons, B., 2008. Climate change: How can the developing countries benefit from the entering into force of the Kyoto Protocol? http://www.dundee.ac.uk/cepmlp/car/html/car7_art icle1.pdf

7. Kartha, et al., 2007. In Navarro, M. 2007. Toward a more student-centred education, analyzing the value of participatory development methods in college teaching. Association for International Agricultural and Extension Education. Internationalizing for Cultural Leadership. 23rd Annual Conference, May 20-24. Vol: 22, Polson, Montana, USA.
8. Organization for Economic Co-operation and Development. 2007. In Navarro, M. Toward a more student-centred education, analyzing the value of participatory development methods in college teaching. Association for International Agricultural and Extension Education. Internationalizing for Cultural Leadership. $23^{\text {rd }}$ annual Conference, Vole: XXII, May 20-24, 2007, Polson Montana, USA.

9. Walt, V., 2008. The world's growing food- price crisis. Time Magazine. USA. Wednesday, Feb. 27.

10. Strauss-Kahn, D. 2008. IMF warns of global inflation, famine. Press TV. 13 April.

11. Smiths, L. and F. Elliott, 2008. Biofuels Threaten Billions of Lives. The Australian. Australia. April, 15, 2008.

12. Arshad, F., 2007. Malaysian Agricultural The Future. In Fifty Years of Malaysian Agriculture, Transformational Issues, Challenges and Direction, Mohamed, F., N. Abdullah, B. Kaur and A. Abdullah (Eds.). University Putra Malaysia, Serdang, Malaysia.

13. Asopa,V. and G. Beye, 1997. Management of agricultural research: A training manual. Module 8: Research-extension linkage. Food and agriculture Organization of the United Nations. Rome, Italy.

14. Walt, V., 2008. The world's growing food-price crisis. Times, Tuseday April, 15.

15. CGIAR. 2008. Understanding and containing global food price inflation. CGIAR News. Retrieved from <http://www.cgiar.org/enews/ may2008/story_19.html> on May.

16. Rivera, W. et al., 2001. Agricultural and Rural Extension Worldwide: Options for Institutional Reform in the Developing Countries. Extension, Education Organization for Co-operation and Communication Service, Research, Extension and Training Division, Sustainable Development Department. Food and Agriculture Organization of the United Nations, Rome, Italy.

17. Alex, G. et al. 2002. Rural extension and advisory services-new directions. Rural Development Strategy Background Paper No. 9, Agriculture and Rural Development Department, The World Bank, Washington, D.C.

18. Katz, E., 2002. Innovative approaches to financing extension for agricultural and natural resource management-Conceptual considerations and analysis of experience. Swiss Centre of Agricultural Extension, Lindau. 
19. Quamar, K. 2002. Global trends in agricultural extension: challenges facing Asia and the Pacific region. SD Dimensions: Knowledge: September 2002 (Food and Agricultural Organisation of the United Nations, Rome, Italy.

20. Farrington, J. et al. 2002. Extension, Poverty and Vulnerability: The Scope for Policy Reform (Final Report of a study for the Neuchatel Initiative), Working Paper, 155, Overseas Development Institute, UK.

21. Solaiman, R. Hall, A., 2004. Extension policy at the national level in Asia. Fourth International Crop SCIEMCE CONGRESS, September 2004 Brisbane, Australia.

22. MalekMohammadi, I. 2005.Towards universal agreecultural extension paradim. A comparative study on agricultural extension system in AIM countries, Australia, Iran, Malaysia. Institute for Agricultural Extension. University Putra Malaysia. Serdang, Malaysia.

23. Devenish, K. 2006. The spoked wagon wheel model of extension for change in agriculture. Proceedings of APEN International Conference 2006 0n Practice Change for Sustainable Communities: Exploring Footprints, Pathways and Possibilities, 6-8 March 2006 at Beechworth, Victoria, Australia.

24. Sarma, C. 2007. Policy framework for agricultural extension (X Plan) Scheme Support to state extension program for extension reforms. Department of Agricultural and Cooperation, Ministry of Agriculture, New Dehli.

25. Hamzah, A. 2007. Agricultural Extension Responsiveness in Malaysia. In Fifty Years of Malaysian Agriculture, Transformational Issues, Challenges and Direction, Mohamed, F., N. Abdullah, B. Kaur and A. Abdullah (Eds.). University Putra Malaysia, Serdang, Malaysia.

26. Hussey, M. 2008. In Texas Cooperative Extension is now AgriLife Extension. By: Mayes, D. January, 2008. Southeast technical Resource Center, Texas A\&M University System, College Station, Texas, USA.
27. Ahmed, A. 2007. Managing Knowledge in the 21st Century and the Roadmap to Sustainability. Greenleaf Publication. Sheffield. UK.

28. Earth Treands. 2005. Agriculture and FoodAgricultural Production Indices: Food production per capita index.

29. Arikan, Y. 2005. Experience of REC Turkey in implementation of UNFCCC ARTICLE. (Education, Training and Public Awareness) at National Level. The regional Environmental Centre REC Turkey.

30. Hulm, D. 1990. Agricultural technology development, agricultural extension and applied social research: Past contributions and future roles. Social Ruralis, 30: 323-335.

31. Vanclay, F. 2005. Submission in response to the Agriculture and Food Policy Reference Group Issues Paper: Ensuring a profitable and sustainable agriculture and food sector in Australia. Tasmania Institute of Agricultural Research. Hobart, Tasmania. Australia.

32. Hellin, J. et al. 2006. The Kamayoq in Peru: Farmer-to farmer extension and experimentation. LEISA Magazine. 22.3. Center for information on Low External Input and Sustainable Agriculture. Amsterdam, the Netherlands.

33. Gibbons, M. et al. 1994. The New Production of Knowledge. Sage, London, UK.

34. Hawkins, B. 2000. Libraries, knowledge management and higher education in electronic environment. ALIA Conference. 24-26 Oct. 2000. Canberra. Australia.

35. Bellinger G. 2004. Knowledge managementemerging perspective. Retrieved March 11, 2008 from: www.systems-thinking.org/kmgmt/kmgmt. htm.

36. Singh, 2002. Research extension-farmer-market linkages to combat hunger and poverty in the Asia and pacific region. FAO Expert Consultation on Agricultural Extension-Research-Extension-Farmer Interface and Technology Transfer, 16-19 July 2002. Bangkok, Thailand. 